PESHAWAR JOURNAL OF PSYCHOLOGY AND BEHAVIORAL SCIENCES, 2019, VOL. 5, NO. 1, 1-18

\title{
The Role of Emotional Intelligence in Organizational Justice Development and LMX in Pakistan International Airlines
}

\section{Junaid Athar Khan ${ }^{1}$}

Abdul Wali Khan University Mardan

The purpose of this study was to identify the relationship between emotional intelligence (EI) and leader-member exchange (LMX) and organizational justice (OJ) in a public sector organization. PIA was the case study of the following research and therefore data was collected from certain selected employees in PIA, while the findings of this study was generalized over the entire employee base of PIA and also over the other public sector organizations of the country. The design of the research is quantitative and the data collection method is primary. A pre-structured questionnaire was used to collect data from 391 employees of PIA. Several statistical techniques such as reliability, correlation, and partial least square method analysis were applied to identify the relationship between the variables. The researcher has also conducted a detailed discussion over the findings of this study, while comparing it with the evaluations carried out by past studies regarding the subject matter under consideration. The findings of the study revealed a positive relationship between EI, LMX and OJ.

Keywords: emotional intelligence, organizational justice, leader-member exchange, Pakistan International Airlines (PIA)

Emotional intelligence represents the capability of an individual to manage and deal with his/her emotions (Bashir, 2016). The use of emotions can be found in different aspects of human-life and emotional intelligence is considered highly important for individuals in their

\footnotetext{
1 Assistant Professor, Institute of Business Studies and Leadership, Abdul Wali Khan University Mardan, Khyber Pakhtunkhwa, Pakistan. contact: junaid@awkum.edu.pk
}

ISSN 2415-6779 EISSN 2518-4474

https://doi.org/10.32879/picp.2019.5.1.1

www.pjpbsicp.com 
personal as well as professional development (Abbasi, Jhatial \& Halepota, 2018). It is subjected to the ability of processing the emotions specific information in the best possible way for the determination of interpretation and the meaning of the emotions (Clarke, \& Mahadi, 2017). The emotional relationship at the workplaces becomes important for the understandability with the perspective of considering the different dynamics of the decision making for leadership at the managerial level (Ahmed \& Nawaz, 2015).

There is a significant amount of efforts made by the researchers in order to investigate the theoretical as well as empirical relationships between the emotional intelligence and leadership role in an organization. The empirical evidence subjected to the emotional intelligence and its potential connection with other variables including the leader-member exchange and organizational justice is less discussed in terms of the presentation of the empirical evidence. Leader-member exchange refers to the relationships that leaders establishes with their subordinates to influence their performance and overall attitude towards the organization (Smith, 2006).

While, organizational justice refers to the overall perceptions of employees regarding the prevailing practices in their organizations in terms of equal treatment and justice and fair dealings (Al-Shammari, \& Ebrahim, 2014). The theoretical perspective is presented by many researchers, which establishes a conceptual relationship between the three important parameters with each other. There is still more chance to investigate the empirical relationship between the three variables by looking at the workspace-oriented dynamics and the professional growth of the individuals (Abbasi, Jhatial \& Halepota, 2018).

The primary aim of the study was to identify the role of emotional intelligence in organizational justice development and leader-member exchange (LMX) in PIA. Investigating the potential relationship between emotional intelligence, LMX, and OJ is important in the case of the public sector organizations because they play a significant role in the development of economic activities in countries. The public sector organizations are governed and regulated by specifically institutionalized mechanisms and bodies such as national investment boards that include the professionals and the economic experts hired by the government in order to take the investment and economic decisions depending upon looking at the possibility of the various successful Paradigms (Ali, Dey \& Filieri, 2015). 
Pakistan International Airlines is one of the significant public sector Institutions of the country, which was formulated by the government to provide national-level aviation services (Abbasi, Jhatial, $\&$ Halepota, 2018). The performance of the organization over the past few decades has not been up to the mark and is questionable due to many different challenges and issues coming in the way of its progress. The relationship between the emotional intelligence, LMX and organizational justice with the perspective of looking at the development of empirical evidence that may provide some of the important facts which can be considered to understand the real-time challenges faced by the institutions in terms of giving out the non-satisfactory performance (Bashir, 2016). Hence, achieving this objective will consequently propose recommendations which PIA could adopt to improve its performance. Based on the primary aim, there are certain objectives that the study will look to accomplish.

- To examine the relationship between LMX and OJ.

- To identify the association between emotional intelligence and LMX.

- To propose recommendations to PIA that can help the firm in reviving its lost status.

PIA and most of the public sector organizations in Pakistan have been underperforming from quite a long time. One of the major reasons behind the failure of PIA, which was once considered as the top international airline in the entire world, is the lack of collaboration between its leadership and the employees. On several occasions, it has been observed that employees and leadership are not on the same page. The incompetence of the leadership has been a reason why the company has performed so miserably (Yusufzai, 2018; Bhatti, 2018; Pakistan Aviation, 2017).

Each government appoints their favored person as the head of the organization and the appointment is not done on merit. It has become an extremely overemployed organization where even the retired employees are provided with great perks despite the fact that the company is going through losses. Due to this lack of competency of the leadership and lack of organizational justice, PIA over the past ten years had incurred a loss of around Rs361 billion (Malkham, 2018). Considering this problem that PIA is facing, it needs a change in the past approaches of the leaders in 
order to develop a positive work environment and also to ensure that the business performs well. This lack of collaboration between the government, PIA's management, and its employees are costing the country severely. In order to deal with this problem, the following study is initiated as it will look to identify whether emotional intelligence in LMX and OJ can be helpful to resolve the problem PIA is facing.

\section{Research Questions}

RQ1: Is there any relationship between emotional intelligence, LMX, and organizational justice within public sector organizations such as PIA?

RQ2: How public sector organizations can enhance their employees' emotional intelligence and motivation to work hard just like in the case of private sector organizations?

\section{Literature Review}

The leader-member exchange and the emotional intelligence may be considered as some important parameters within the organizational frameworks to look at the ability of the individuals to perform better in terms of giving out the maximum level of the creativity. (Karim, 2008). The emotional intelligence and the leader-member exchange can potentially contribute a lot in terms of the determination of the creativity as well as the capacity of the employees working within a particular organization. The relationship can be established on the basis of looking at the theoretical perspective, and the empirical evidence can be located and found out on the basis of performing a certain level of the quantitative analysis (Saeed, Waseem, Sikander \& Rizwan, 2014).

The emotional intelligence and leader-member exchange is usually considered a strong predictor for the creativity, and there are some of the opinions which signal out the leader-member exchange to be the predictor of the creativity within the employees with the emotional intelligence to be subtracted out in this model that is leader exchange theory model. It gives an idea that how creative an employee could be, if they are guided appropriately through effective leader-member exchange environment. It is also evident that leaders can better guide and motivate their employees to think and work creatively, which is one of the main feature of this model.

PESHAWAR JOURNAL OF PSYCHOLOGY AND BEHAVIORAL SCIENCES, 2019, VOL. 5, NO. 1, 1-18 
The combination of emotional intelligence and leader-member exchange negatively influence the creativity and the ability of the employees to perform better at workplaces. The creativity of the employees plays a very vital role in the overall organizational potential to perform well and to outclass its other potential competitors in terms of achieving the various organizational objectives in the most efficient way. The leader-member exchange and its potential relationship with the creativity make it an important factor for the organizations to consider in terms of their policy-making and specifically the employee's specific procedural guidelines which are set for the convenience of performing the various tasks efficiently (Riaz et al., 2018).

Emotional intelligence is an important factor in managing employee's emotions and their internal state of mind as it is subjected to the capacity of the employees to recognize and estimate their own emotions in relation to the emotions of the others as well. The emotional information becomes important in order to potentially guide and make the employees to think about appropriately managing and adjusting the emotions in accordance with the emerging situation and the environment. The control of the emotional intelligence at the workplaces can provide the employees with a better opportunity to bring themselves at a place which can provide better chances of achieving the various organizational and the work-related goals and the aims (Nawaz, Bhatti, Ahmad, \& Ahmed, 2018).

There are different theoretical models which are used to highlight the different aspects of emotional intelligence and to illustrate the significant use of emotional intelligence at people places and other suitable places. The emotional intelligence may be considered as important for the leaders and the managerial roles within the organization in order to understand the various aspects of leading the employees in the best possible way within a particular organization. The lack of the understanding of emotional intelligence within the organizations can potentially become a problem for the entire organization as the leader, and the top manager will not be able to look at the different aspects of the employee's specific emotions and their dynamics (Nasir \& Mahmood, 2016).

Goleman (2001) illustrated and defined the emotional intelligence as the array of the skills and the properties which can derive the leadership specific performance. There is another model known as the trade model, and it demonstrates that the behavioral dispositions and the 
abilities pertaining to the self-perception of the individuals are important within the workplaces or any other suitable places in connection with the measurement of self-reporting abilities. The ability model which came out in the year 2004 potentially focuses on the development of the individual level ability for the processing of the emotional information and data by using the various navigational methods to better illustrate the social environment and the circumstances surrounded by that particular individual (Mushtaq, Bhatti, Ahmad \& Ahmed, 2018). The studies potentially highlighted that emotional intelligence carries certain high attributes that can help the individuals in attaining high level of mental health and internal satisfaction that is directly linked to the outstanding performance of such employees within their organizations and also enable the leaders in establishing better understanding of their employees and achievement of high level of leader-member exchange benefits (Karim, 2008).

The research indicates the fact that emotional intelligence is related to the job-specific performance and there has been a positive relationship between both of these which is potentially found in many of the research studies. There are some studies which indicate that there is no relationship or an inconsistent relationship present between the jobspecific performance and emotional intelligence. The compensatory model tries to link up the emotional intelligence with General Intelligence with the perspective of illustrating the fact that the job performance may potentially become positive due to the fact that cognitive intelligence decreases (Clarke \& Mahadi, 2017). Employees with low IQ level potentially tend to get a higher level of task performance, and the subsequent emotional intelligence also is perceived as at the high level for this particular case. The potential relationship between work attitude and emotional intelligence seems to be less consistent or less related. There are some of the recent studies which potentially indicate the fact that the emotional intelligence may not be necessary for received as a positive characteristic for the property at the universal level. These types of studies indicate the existence of a negative correlation between emotional intelligence and managerial work requirements (Karim, 2011).

The leader-member exchange relationships may be perceived as trust-based relationships which can be derived by the respect and other forms of the emotional relationships, and the work-oriented scope of their applicability within the workplaces of the organizations cannot be

PESHAWAR JOURNAL OF PSYCHOLOGY AND BEHAVIORAL SCIENCES, 2019, VOL. 5, NO. 1, 1-18 
restricted. The leadership member exchange theory for the framework explains the growth of a vertical dyadic organizational influence and its potential relationship with the team-oriented performance during the selection and other decisions to be taken by the leadership (Bashir, 2016). This theoretical perspective focuses on the illustration of the fact that the leader's potential is to select the best option in order to provide the best chance of the acceptability for the members or other subordinates to accept. The employees are the subordinates working under the business leaders and which may develop strong emotional relationships with the perspective of considering the mentorship provided by the seniors and the leaders at the workplace. This potentially can become one of the important reasons for the employees to get engaged in the team-specific work at the accomplishment of certain projects in a more productive way. It can be considered as a very positive relationship for both parties and the enhancement of the overall work-oriented quality at the workplaces (Balkhi, Khan, Jawed \& Khan, 2016).

LMX Potentially focuses on the illustration and demonstration of the different effects which the leadership qualities and behavior may potentially put on the subordinates and teams operating within a particular organization. This theoretical framework focuses on the fact that the leaders formulate strong trust and the emotional relationship with some of the potential subordinates and the team members. The main focus of this particular conceptual framework is the establishment of the fact that the leaders at the workplace or other institutional framework does not consider all the subordinates equally. This potentially becomes important to consider the leadership-oriented practices and the behavior shown by the individuals in order to positively utilize the various facts in the best interest of organizational performance (Ali, Dey \& Filieri, 2015).

There is a possibility of establishing a relationship between the leadership qualities, work specific roles and the emotional intelligence based upon the LMX. This can substantially provide a basis for understanding the different problems and the challenges of the workplaces which are connected with the behavior and the attitude shown by the workers. There is a possibility of connecting the LMX with the job embeddedness in terms of its potential connection with the higher rate of job-specific satisfaction as well (Ahmed\& Nawaz, 2015).

The different type of organizations processes a different type of leadership styles, and the public sector organizations are usually 
discussed with the perspective of questioning about the employee specific productivity. The public sector organizations perceive the concept of a low level of motivation and interest among the employees in order to conduct their job-specific roles in the duties at the places. The different features and the analysis about understanding the various reasons for more chances of giving out the low level of the performance within the public sector organizations is an important topic to look at for the researchers.

The investigation of the various facts can potentially become significant in order to understand the real reasons behind the challenges faced by the public sector organizations and their leaders to make their organizations productive. The employee specific performances make the overall impact on the overall organizational performances as individual performances are directly related to organizational performance as a whole. The various reasoning and the potential findings to compare them with the private sector organization and the productivity of the employees in them is an important subject to explore nowadays (Balkhi, 2016).

The relationship of the emotional intelligence, LMX and organizational justice with the perspective of the employee's specific perception about the organizations is an important topic to look at. This becomes important for the public sector organizations as they usually face with many performance specific challenges and the reasons behind the usual problems faced by the public sector organizations are yet to be investigated by most of the researchers.

The emotional intelligence may be considered as an important parameter which has to be understood by the leadership of the organizations. The similar applies to the LMX, and there is the possibility of a direct relationship with both of the parameters in connection with the employee specific productivity as well as the performance. This can be connected to the organizational justice with the perspective of giving the opportunities to the different employees to speak out their perception about the organization. All the different parameters including the emotional intelligence, LMX, and organizational justice or interrelated with each other with the theoretical perspective which needs to be interrelated in terms of the empirical evidence and the subsequent analysis performance (Ahmed \& Nawaz, 2015). 


\section{Conceptual Framework}

Based on the literature and its findings, the given study proposes the below depicted (figure 1) conceptual framework for the study.

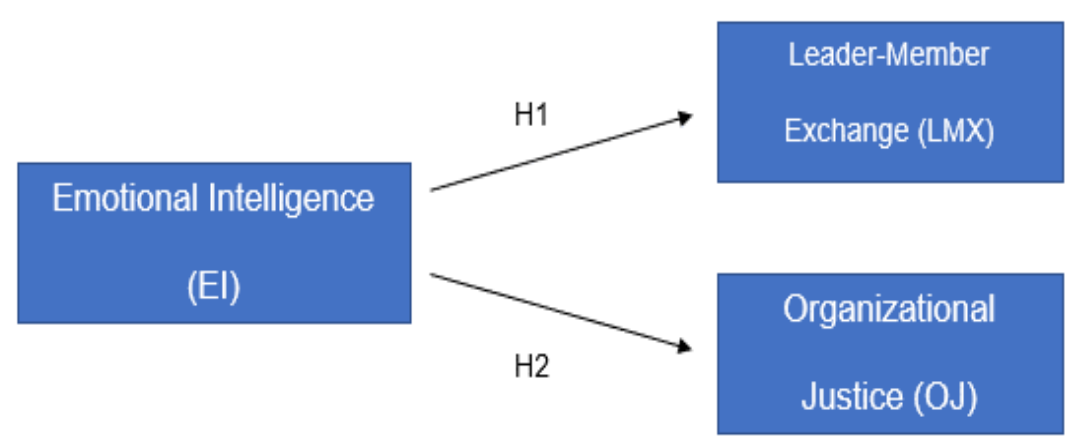

Figure 1: Conceptual Framework

Emotional intelligence is the independent variable whereas LMX and OJ are the dependent variables. Goleman (2001) illustrated and defined the emotional intelligence as the array of the skills and the properties, which can derive the leadership specific performance. The LMX relationships may be perceived as trust-based relationships that can be derived by the respect and other forms of the emotional relationships, and the work-oriented scope of their applicability between a leader and the members of an organization. Lastly, OJ is the fairness that is maintained within the organization. Hypotheses for the study are:

H1: EI will be positively associated with LMX

$\mathrm{H} 2$ : EI will have a positive relationship with OJ

\section{Sample}

\section{Method}

The sample comprised of three hundred and ninety-one ( $\mathrm{N}=391)$ employees of PIA serving in various cadres. Data was collected from the major stations of PIA that included Peshawar, Karachi, Lahore, Islamabad, and Quetta through convenient sampling technique as the random sampling was not possible due to busy schedule of the employees of PIA during their working hours. 


\section{Instrument}

The researcher used a pre-structured adapted questionnaire adapted from study of Clarke and Mahadi, (2017) comprising of 29 items. The questionnaire comprised of four sub-scales and demographic information. The sub-scales of the questionnaire included employee's turnover intentions, emotional intelligence, LMX, and organizational justice. It is a 5 point Likert scale for measuring the responses of the participants. All four sub-scales consisted of 6 items each, and 5 questions were related to demographic information. In the present study three sub-scales that included emotional intelligence, LMX, organizational justice and demographic questions were used for data collection from the selected sample of the study.

\section{Procedure}

The selected sample of the study were contacted after seeking prior permission from the competent authority. After initial rapport building and briefly explaining the purpose of the study the participants were individually distributed questionnaires in a fixed sequence and they were requested for their honest opinions on every question. The participants were assured of confidentiality of their results and were briefed that the results will be displayed in group form and not individually. The purpose individually collection of data was due to unavailability of group of participants from each station at one time due to their work schedule during working hours.

\section{Result}

Table 1

Reliability Analysis (N=391)

\begin{tabular}{lcc}
\hline Scales & Items & Cronbach's Alpha \\
\hline Emotional intelligence & 6 & 0.77 \\
LMX & 6 & 0.81 \\
Organizational justice & 6 & 0.94 \\
\hline
\end{tabular}

Table 1 shows the alpha reliability of the three sub-scales of the study. The result reveals moderate to high reliability of all the three subscales of the study.

PESHAWAR JOURNAL OF PSYCHOLOGY AND BEHAVIORAL SCIENCES, 2019, VOL. 5, NO. 1, 1-18 
THE ROLE OF EMOTIONAL INTELLIGENCE IN...

Table 2

Profiling of Participants $(N=390)$

\begin{tabular}{llcc}
\hline Variable & \multicolumn{1}{c}{ Category } & Frequency & Percent \\
\hline Gender & Male & 263 & 67.26 \\
& Female & 127 & 32.48 \\
Age in years & $18-25$ & 54 & 13.81 \\
& $26-35$ & 182 & 46.55 \\
& $36-50$ & 133 & 34.02 \\
Education & 51 and above & 21 & 5.37 \\
& High school & 165 & 42.20 \\
& Graduate & 183 & 46.80 \\
Occupation & Post-graduate & 42 & 10.74 \\
& Operational level & 48 & 12.28 \\
& Tactical level & 240 & 61.38 \\
& Strategic level & 102 & 26.09
\end{tabular}

Table 2 outlines the profile or the demographic information about the participants of the study. More than 67 percent of the respondents were male because of the fact that Pakistan is a male-driven society where males occupy the majority of the employment. Similarly, only $13.3 \%$ of the participants were between the age of 18 and 25 whereas more than $32 \%$ were below the age of 35 . This indicates that PIA lacks youth as most of its employees are not younger in age. One surprising finding portrays that around $42.3 \%$ of the PIA employees had the qualification of high school which is quite below the standards accepted worldwide. This indicates that the appointments are not done on merit in the organization.

Table 3

Correlation analysis

\begin{tabular}{lccccc}
\hline & Mean & SD & OI & EI & LMX \\
\hline Organizational Justice & 3.07 & 0.92 & & & \\
Employee's Emotional & 2.68 & 0.90 & $.29^{* *}$ & & \\
Intelligence & & & & & \\
LMX & 3.01 & 0.86 & $.61^{* *}$ & $.37^{* *}$ & \\
Employee's Turnover & 3.03 & 0.83 & $.342^{* *}$ & $.382^{* *}$ & 0.02 \\
intentions & & & & & \\
\hline
\end{tabular}

Note: $* * \mathrm{p}<.01, * * \mathrm{p}<.05$

PESHAWAR JOURNAL OF PSYCHOLOGY AND BEHAVIORAL SCIENCES, 2019, VOL. 5, NO. 1, 1-18 
Table 3 shows that EI is positively associated with LMX and OJ. This finding supports $\mathrm{H} 1$ and H2. It was also found that LMX is also positively associated with organizational justice. Correlation between the variables can be observed as the significant value in all the variables is above 0.05 and 0.01 , which indicates that OJ, EI, and LMX are all positively and significantly related to one another. These findings are in relation to the findings obtained by Al-Shammari and Ebrahim (2014) which identified that there is a positive relationship between LMX and OJ. Similarly, the findings are also complying the findings of Karim (2008) which concluded that a positive association exists between EI and LMX. Smith (2006) also indicated that LMX is significantly influenced by the level of emotional intelligence of the leaders within an organization.

\section{Table 4}

Partial Least Square Method (N=391)

\begin{tabular}{llllll}
\hline Block & Loadings & $\mathrm{t}^{\text {values }}{ }^{\mathrm{a}}$ & $\begin{array}{l}\text { Cronbach's } \\
\text { Alpha }\end{array}$ & $\begin{array}{l}\text { Composite } \\
\text { Reliability }\end{array}$ & $\mathrm{AVE}^{\mathrm{c}}$ \\
\hline ROE & 0.88 & 12.18 & & & \\
LMX & & & & 0.78 & 0.71 \\
LMX_1 & 0.76 & 27.87 & 0.92 & & \\
LMX_2 & 0.82 & 16.62 & & & \\
LMX_3 & 0.76 & 22.45 & & & \\
LMX_4 & 0.84 & 9.89 & & & \\
LMX_6 & 0.85 & 8.45 & & & \\
LMX_7 & 0.88 & 34.21 & & & \\
\hline EI & & & & & \\
EI_1 & 0.86 & 14.23 & 0.84 & & \\
EI_3 & 0.76 & 6.49 & & & \\
EI_4 & 0.82 & 19.78 & & & \\
EI_5 & 0.64 & 21.25 & & & \\
\hline OJ & & & & & \\
OJ_1 & 0.64 & 7.21 & 0.91 & & \\
OJ_2 & 0.68 & 16.71 & & & \\
OJ_3 & 0.72 & 18.81 & & & \\
OJ_4 & 0.83 & 21.98 & & \\
OJ_5 & 0.54 & 5.92 & & \\
OJ_6 & 0.65 & 6.88 & & & \\
\hline
\end{tabular}

PESHAWAR JOURNAL OF PSYCHOLOGY AND BEHAVIORAL SCIENCES, 2019, VOL. 5, NO. 1, 1-18 
Table 4 shows t-values calculation is done on the basis of bootstrapping with 391 sample size. The results indicate that variance exceeds the threshold value of 0.50 . The PLS path analytic model is used to develop a predictive chart for estimating the different values for the EI, LMX and the OJ.

\section{Discussion}

Although a great deal of research has examined the relationship between LMX and OJ and between the EI and OJ, but none of the studies (to our knowledge) has conducted an empirical evaluation on the relationship between EI, LMX, and OJ jointly. A number of researchers have examined the role of mediating variable, while linking the EI with various outcome variables, for example, the studies conducted by Kafetsios and Zampetakis, (2008), Karim, (2009) and Vratskikh et al., (2016); however, there are still lots of such untouched variables that can still need investigation for their mediating role between the EI and other variables, particularly the organizational justice. In this regard, Yung Woo Jung, (2014) suggested to evaluate the impact of Emotional Intelligence on other variable, while considering the role of LMX as one of the possible mechanism in defining such relationships.

The hypotheses this study received considerable support from the collected data. The results revealed that there is a positive relationship between EI and LMX; for instance, the employee will perceive a high LMX relationship, is he/she is more emotionally intelligent. Thus the results of the study confirmed the predictions of Woo Jung (2014) that high-quality LMX relationships could be predicted by the presence of high Emotional Intelligence among the employees on an organization. Similarly, the findings of the study conducted by Clarke and Mahadi, (2016) suggested that emotionally intelligent people are more likely to become members of leaders in a group. It was further evaluated that the ability to appropriately using emotions, the ability to effectively managing emotions, and the ability to identify emotions in an accurate manner would lead to the development of high-quality LMX traits among employees.

The results of this study also revealed that LMX has a positive relationship with organizational justice. The findings of the study in this regards are highly consistent with the findings of the studies conducted by Sui, Wang, and Wang, (2015) and He et al., (2016), who evaluated that when employees have high quality of LMX relationships, they

PESHAWAR JOURNAL OF PSYCHOLOGY AND BEHAVIORAL SCIENCES, 2019, VOL. 5, NO. 1, 1-18 
perceive high quality of organizational justice in organizations. It is found that EI establishes high-quality LMX traits among employees of an organization, which in turn build a healthy environment in the organization and promotes good perceptions among the employees in the prevailing level of justice in their respective organizations.

Finally, the study evaluates that there is a strong relationship between all three variables; LMX, EI, and OJ. The finding shows a high level of correlation among all the three variables and especially between the EI and OJ and LMX and OJ. It is provided that EI shows a high level of improvement in the LMX level among employees, which in turn improves their confidence in the organization's leadership and creates positive perceptions about the overall justice system of the organization.

Thus, it become highly important for the modern world organization to enhance the level of EI among employees in order to achieve a higher level of LMX and organizational justice in the organization. Similarly, a just and effective work environment increases emotional intelligence and LMX level among the employees in the long run. The study conducted by Titrek et al., (2014) strongly supports this perspective of the study; the authors commented that emotional intelligence and LMX are developmental in nature and therefore, the situation of organizational justice can frame the relationship of these two variables with the organizational justice and among their selves.

\section{Conclusion}

The main purpose of this study was to identify the relationship between emotional intelligence and leader-member exchange and organizational justice. The main problem that enabled the researcher to initiate the study was the incompetent leadership that led to the decline of PIA. PIA was the case study of the given quantitative research and therefore data were collected from all the employees in PIA. A prestructured questionnaire was used to collect data from 390 employees of PIA. Several statistical techniques such as reliability, correlation, and partial least square method analysis were applied to identify the relationship between the variables. The findings of the study indicate that a positive relationship exists between EI and LMX as well as between EI and OJ. The findings are similar to the findings of Shammari and Ebrahim (2014), Karim (2008) and Smith (2006). Based on the carriedout research, it is concluded that if PIA intends to enhance its 
performance, it must endorse emotional intelligence skills in its leadership, so that they can develop a positive relationship with the employees and promote organizational justice.

\section{Recommendations}

After analyzing the current condition of PIA, it is recommended that the company should develop a collaborative environment between employees and the leadership for the long-term betterment of the organization. Employment should be done based on merit rather than 'sources' which is very common in Pakistan and secondly, the company should hire millennials and youth to make use of their talent considering the fact that the youth is the backbone of any country.

Furthermore, the company needs to reduce the size of the organization by downsizing the employees that are not appointed on merit. The government should appoint leaders who possess high emotional intelligence skills. Similarly, training sessions should be organized to develop emotional intelligence skills within the leaders, management as well as the employees. The government should develop a committee that would overlooks on the governance of PIA which has been devastated since the past two decades and is also a reason behind the decline of the mighty airline

\section{Limitations and Future Implications}

There were certain limitations faced by the researcher during the course of the study. Based on these limitations, future implications would be proposed in this section. Due to limited time and budget, the study adopted a cross-sectional approach. It focused on a single organization i.e. PIA and for a limited time period. The scope of the study was also limited due to the time restrictions. Keeping in mind this limitation, it is recommended that the future researchers may carry out a longitudinal study on either the same variables or changing the variables and keeping the same organization to propose other recommendations through which the public sector organizations in developing countries like PIA in Pakistan can improve their performance. Future researchers might consider some other public sector organization such as Pakistan Steel Mill which is also underperforming to test the authenticity of the present

PESHAWAR JOURNAL OF PSYCHOLOGY AND BEHAVIORAL SCIENCES, 2019, VOL. 5, NO. 1, 1-18 
study and also to test the variable within the context of some other organization.

\section{References}

Abbasi, K. H., Jhatial, A. A., \&Halepota, J. A. (2018). Corporate Governance in Pakistan: An Exploratory Study of the Pakistan International Airlines Corporation Limited. Grassroots, 52(1), 246-260.

Ahmed, M., \& Nawaz, N. (2015). Impact of organizational commitment on employee turnover: A case study of Pakistan International Airlines (PIA). Industrial Engineering Letters Journal, 5(8).

Ali, F., Dey, B. L., \& Filieri, R. (2015). An assessment of service quality and resulting customer satisfaction in Pakistan International Airlines: Findings from foreigners and overseas Pakistani customers. International Journal of Quality \& Reliability Management, 32(5), 486-502.

Al-Shammari, M., \&Ebrahim, E. H. (2014). The relationship between leader-member exchange and organizational justice: Empirical evidence from Bahrain. European Journal of Business and Management, 6(34), 285-293.

Bashir, I. (2016). A Study of Emotional Intelligence Based Instructional Leadership Styles and related Indicators at University Level in Pakistan. NICE Research Journal, 36-45.

Bhatti, H. (2018). Political interference, lack of professional leadership behind PIA's chronic losses. Retrieved from: https://www.dawn.com/news/1436355

Clarke, N., \& Mahadi, N. (2017). Differences between the follower and dyadic measures of LMX as mediators of emotional intelligence and employee performance, well-being, and turnover intention. European Journal of Work and Organizational Psychology, 26(3), 373-384.

Karim, J. (2008). The relationship between emotional intelligence, leader-member exchange, and organizational commitment. Euro Asia Journal of Management, 18(2), 153-171.

Karim, J. (2011). Emotional intelligence, leader-member exchange, organizational justice, and outcome variables: A conceptual model. International Journal of Leadership Studies, 6(3), 390411.

PESHAWAR JOURNAL OF PSYCHOLOGY AND BEHAVIORAL SCIENCES, 2019, VOL. 5, NO. 1, 1-18 
THE ROLE OF EMOTIONAL INTELLIGENCE IN...

Karim, J., 2008. The relationship between emotional intelligence, leadermember exchange, and organizational commitment. Euro Asia Journal of Management, 18(2), pp.153-171.

Malkham, A. (2018). PIA, PSM suffer Rs552 bn loss in 10 years, audit reveals. Retrieved from: https://www.thenews.com.pk/print/398206-pia-psm-sufferrs552-bn-loss-in-10-years-audit-reveals

Mushtaq, M. N., Bhatti, G. A., Ahmad, S., \& Ahmed, Z. (2018). How Can the Organizational Commitment of Pakistan Railways' Employees Be Improved? The Moderating Role of Psychological Capital.

Nasir, S. Z., \& Mahmood, N. (2016). Determinants of Employee Retention: An Evidence from Pakistan. International Journal of Academic Research in Business and Social Sciences, 6(9), 182194.

Nawaz, M., Bhatti, G. A., Ahmad, S., \& Ahmed, Z. (2018). How can the organizational commitment of Pakistan Railways' employees be improved? The moderating role of psychological capital. Journal of Entrepreneurship, Management, and Innovation, 14(1), 123142.

Pakistan Aviation. (2017). Five major issues in PIA. Retrieved from: http://pkaviation.com/2017/03/23/five-major-issues-faced-bypia/

Riaz, Z., Arif, A., Nisar, Q. A., Ali, S., \&Sajjad, M. (2018). Does Perceived Organizational Support influence Employees Emotional labor? Moderating \&Mediating role of Emotional Intelligence. Pakistan Journal of Humanities and Social Sciences, 6(4), 526-543.

Saeed, I., Waseem, M., Sikander, S., \&Rizwan, M. (2014). The relationship of turnover intention with job satisfaction, job performance, leader-member exchange, emotional intelligence, and organizational commitment. International Journal of Learning and Development, 4(2), 242-256.

Smith, M.L., (2006). Emotional intelligence, leader-member exchange, and individual contributions to organizational social capital. Sharing network leadership, 169, p.190.

Virdee, P. (2018). Women and Pakistan International Airlines in Ayub Khan's Pakistan. The International History Review, 1-26. 
Yusufzai, A. (2018). PIA's Accumulated Losses to Cross Rs 48 Billion in 2018. Retrieved from: https://propakistani.pk/2018/10/09/piasaccumulated-losses-to-cross-rs-48-billion-in-2018/ 